\title{
Creation of intelligent management systems in construction
}

\author{
Leonid Zelentsov ${ }^{1}$, Liya Mailyan ${ }^{1, *}$ \\ ${ }^{1}$ Don State Technical University, pl. Gagarina, 1, Rostov-on-Don, 344010, Russia
}

\begin{abstract}
The article deals with the problems of creation of intelligent management system by investment and construction projects. The relevance of research is due to the fact that in modern Russian construction there are frequent delays in terms of construction, the excess of budgets in the projects and low quality products. One of the main reasons of this situation is the poor organization of the production process at the construction site and that leads to a significant loss of workers' time and construction machinery, to an inefficient use of material resources. The creation of intelligent management system in construction implies a fundamental change in the construction management technology starting from the date of fixation and transmission of information from the construction site, its systematization and finally development and making management decisions. The introduction of intelligent management system means a significant increase of registered options and data volumes while increasing its transmission speed at the construction site and that determines the need for developing the appropriate information technology and the Internet use.
\end{abstract}

\section{Introduction}

Currently, a large part of the domestic construction companies was not able to respond adequately and consciously to the constantly changing conditions of external and internal environment. Also this refers to the construction companies with a good management mechanism of industrial and economic activity. In this regard, there is a need to conduct a series of studies aimed at the development of adaptive management mechanisms for construction companies and the creation of intelligent management systems. The construction company represents a complex dynamic system with discrete time. Dynamic systems are the systems which change their state in time under the influence of external and internal forces [1]. Construction due to its features is a dynamic system with discrete time.

\section{Experimental section}

\footnotetext{
${ }^{*}$ Corresponding author19liechka84@mail.ru
} 
In the process of implementation of $\mathrm{z}$ investment and construction project (ICP) the action of the system (or what is the same, the trajectory of the system in the phase space) is described by the sequence of states $\hat{O}_{z}\left(t_{i}\right)[1,2]$.

$$
\begin{gathered}
\hat{\mathrm{O}}_{z}\left(t_{i}\right)=\left\{\hat{\mathrm{O}}_{z}\left(t_{i}\right)_{1} \rightarrow \hat{\mathrm{O}}_{z}\left(t_{i}\right)_{2} \rightarrow \hat{\mathrm{O}}_{z}\left(t_{i}\right)_{3} \rightarrow \cdots \rightarrow \hat{\mathrm{O}}_{z}\left(t_{i}\right)_{n}\right\} \\
\hat{\mathrm{O}}_{z}\left(t_{i}\right)=f\left(t_{i}\right)\left\{T_{z}, S_{z}, H_{z}\right\}
\end{gathered}
$$

Where $\hat{O}_{z}\left(t_{i}\right)$ vector of state of $\mathrm{z}$ investment and construction project in the $\left(t_{i}\right)$ discrete interval of planning, $f\left(t_{i}\right)\left\{T_{z}, S_{z}, H_{z}\right\}$ - characteristics of the state $z$ ICPin the $t_{i}$ discrete interval of planning, respectively duration $\left(T_{z}\right)$, net cost of $\left(S_{z}\right)$, reliability $\left(H_{z}\right)$.

In the simulation of management processes three types of control are usually considered: open, or open-ended, closed, or closed-loop control, and adaptive [5]. The adaptive management is characterized by the presence of a closed model of the managed object, in which the possible consequences of control (forecast) are analyzed. In the system-wide plan the adaptation is the ability of the system to detect purposeful adapted action in the current environment, as well as the very process of this adjustment [2].

Along with the concept of adaptation the notion of adaptive management has become widespread $[2,5,8,9]$. It is the system in which, as a result of changes in the external and internal environment options, the corresponding adjustment of the organizational structure and management system, as a whole, appears and that ensures the functioning of the object management $[5,6,11,13]$.

At the macro level the construction management system can be seen as an adaptive model of the closed-loop control (Figure 1).

\section{External environment}

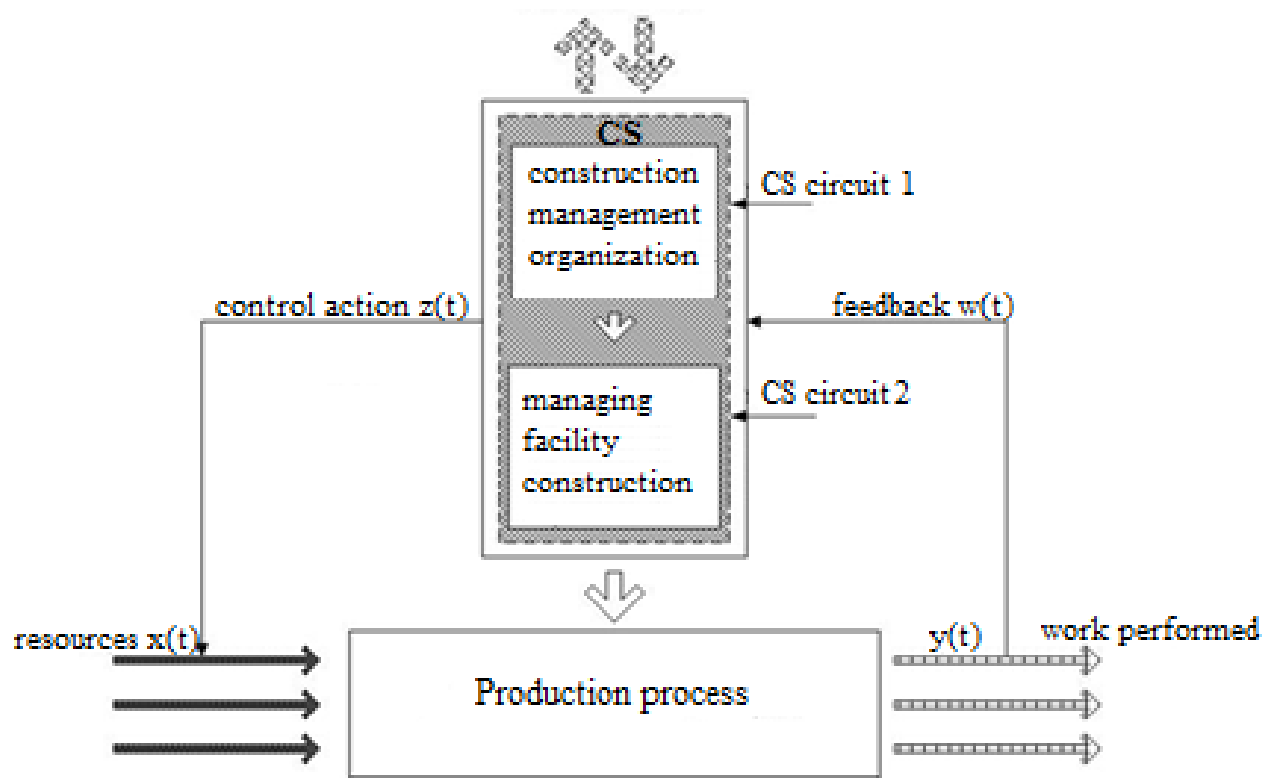

Fig. 1.Adaptive Model of Construction Management.

The model includes the following elements:

1. Object of control- production process, which is a complex work performed at a certain time interval $t_{i}$ for the purpose of erecting one or more structural elements of the building or structure; 
2. External environment - demand of the quality of work, the system of payments for work performed, financing mechanisms, taxation system, etc : $\vec{x}(t)$ - vector of input options of the control object, describing the resources used $\vec{y}(t)$ - vector of output options of the control object, characteristics of work performed on the structural elements.

3. Direct link - command effects produced by the management system;

4. Feedback - is the flow of information that characterizes the efficiency of the flow of the production process and use of resources.

The control system (CS) includes two circuits: CS-1 - circuit of the construction company control and CS-2 - circuit of direct construction object control. CS-1 - is the central department of construction company management, and CS-2 - is a linear ETW (foremen, craftsmen) engaged in the management of the facility construction.

The need for having two circuits in the control system is connected with the high degree of its decentralization, which is due to non-stationary character of production and the territorial disconnection of the facilities construction.

Each circuit implements certain functions and solves specific tasks. So, in the circuit CS-1 the task of preparing the construction production is carried out. The ultimate goal of solving the tasks in the CS-1 is to ensure construction facilities with all the necessary resources: material, labor, construction machinery and mechanisms with the synchronization of their delivery terms to the objects in accordance with the calendar plans of works.

An important condition for the development and adoption of the best management solutions in the circuit CS-1 is to get from the circuit CS-2, if it is possible, more complete and accurate information about the characteristics of the production processes that take place during the construction of the facility.

Circuit CS-2 is focused on the execution of planned tasks developed in the circuit CS-1 and fixing the options of the production processes of the construction: the executed amount of work and resources used in the process of production (workers, construction equipment, materials and structures).

Currently, at the Russian market there is quite a large number of information technologies (IT) designed as universal software products that are not focused on a certain activity and do not allow to specify the main features of building production: Primavera, Project Planner; Rillsoft Project; Microsoft Project. [7]

In specialized IT [7] Russian producers automated functional areas of construction management related to the system of planning, accounting and calculations with customers on the basis of the current pricing system (SEST) and there are no subsystems, allowing to manage the production based on market - company standards.

One of the unsolved problems still is the lack of software package formalizing the management process on the construction site. This is largely due to the absence, until recently, of the technical possibilities for the collection and transmission of operational information at the time of its occurrence on the site. Currently, with the presence of highspeed access to the global network Internet, this problem can be solved effectively.

That's why we are working on the creation of an intelligent management system (IMS) based on computer technology that would provide feedback to the construction facility in real time, which will provide necessary adaptability of ICP management.

Creating intelligent management system in construction requires a fundamental change in the construction management technology starting from the date of fixation and transmission of information from the construction site, its systematization and finally development and making management decisions. A distinctive feature of the IMS from the existing IT is the availability of knowledge accumulation in addition to the database, or as it is now called the base of precedents. 
The knowledge accumulation involves the accumulation of a systematic form of indicators characterizing variants of administrative decisions fully produced or already adopted. It is necessary to distinguish between the decision-making procedure and the corresponding indicators at the operational and tactical command. Interval review (planning) on the operational management stage is a month, a week, a day; on the tactical management stage is the whole period of implementation of the IMS, a year, a quarter.

On the stage of operational management the decision-making procedures are based on the detailed information and are aimed at preventing irregularities in the rhythm of production of a given work, the localization of the causes leading to the emergence of overheads on the construction site. The adoption of tactical decisions is based on aggregate information and macroeconomic indicators, allowing to predict the future state of the system when making certain control actions.

Such decisions at the tactical level of IC management can be a change in terms of individual work performance or construction facility as a whole by adjusting the relationship works (alignment paralleling), increase or decrease the intensity of their performance. When deciding on a tactical level the predictive value of the cost and the term of completion of the object are calculated.

The project manager is always has a dilemma: to break the contract construction period and to get to sanction or not to change the period of construction of the forecast with a significant increase in costs.

The introduction of intelligent management system means a significant increase of registered options and data volumes while increasing its transmission speed at the construction site and that determines the need for developing the appropriate information technology and the Internet use.

To implement this approach in DSTU the IMS "Construction" is being developed as part of subsystems which enable to simulate the management processes in the following functional areas: preparation of construction production; operational management of the construction project; material - technical support for construction projects; management of its own production of concrete and metal products; the operation control of machinery and mechanisms; management accounting and budgeting ICP; quality control of work.

Unlike existing IT the IMS "Construction" is integrated on a single platform of subsystem management accounting and operational management of the construction project for the collection, processing and analysis of the current state of the main control options of the construction object management $[16,17]$.

To provide feedback to the construction facility in the operational management subsystem the software system has been developed -the automated workstation of a manufacturer of works (AWS "Manufacturer of work").

The reference for the tasks implemented in AWS "Manufacturer of work" is the information coming from the adjacent subsystems: weekly and daily plan of works; lists of teams of workers assigned to the object; schedule of construction machinery on the object in the coming week.

In AWS "Manufacturer jobs" a foreman enters data into the document templates daily: work performance log; timesheets of workers' working time; log of operation of construction machinery and mechanisms; log of inspection acts of hidden works; register of overhead material resources received for the object.

The main task of a foreman is to enter, in the table, data of the spent time of workers with an indication of the work on which they are used. In addition, the foreman may also enter the information about a pattern of cause and amount of non-productive time loss.

After entering data on the report card, the labor costs calculations on the report card and work performance log shall be calculated. Until there is a balance of labor costs determined by the report card and work performance $\log$, the foreman cannot "close the day", and send 
the information to the central office of a construction company. In case of hiding the idle time at work, all responsibility for failure in the amount of work, and as a result, the lost productivity, and violation of work performance terms will be imposed on a foreman. In fact, on a daily system the foreman takes photo of the working day activities (PhWD).

The amount of work recorded in the work performance log can be grouped: by performers - a team of workers, structural elements (SE). Actually labour costs on the types of work are determined on the basis of time sheets of the worked hours. With all these data, as well as the information about the loss of time, a detailed analysis of the use of time can be carried out, and calculations of labor productivity (output, coefficient of performance of norms of production), and coefficient of using workers on their major works can be made. A similar analysis can be made on the use of the construction machinery and mechanisms.

Based on the AWS information "Manufacturer of work", the accumulation and aggregation of information, and also the calculations of the indicators characterizing the efficiency of workers and construction machinery are carried out.

\section{Results section}

On the operational management stage ICP such indicators are:

1.The cumulative level of time $\operatorname{losses} U_{z}\left(t_{i}\right)$ (whole-shifting and inside-shifting downtime), workers $U_{z}^{r}\left(t_{i}\right)$, construction machinery and mechanisms (CM\&M) $U_{z}^{m}\left(t_{i}\right)$, has appeared on the interval of planning $t_{i}$ in $\mathrm{z}$ ICP.

$$
\begin{gathered}
U_{z}^{r}\left(t_{i}\right)=\sum_{t=1}^{t_{i}} \sum_{l=1}^{L} u_{t l z}^{\mathrm{r}} \\
U_{z}^{m}\left(t_{i}\right)=\sum_{t=1}^{t_{i}} \sum_{l=1}^{L} u_{t l z}^{m}
\end{gathered}
$$

Where $u_{t l z}^{\mathrm{r}}, u_{l z}^{m}$ - Respectively idle workers and CM\&M ona $\mathrm{t}$ working day; for $\mathrm{L}$ reasons for non-productive losses.

2. Coefficients $K_{z}^{q}\left(t_{i}\right), K_{z}^{m}\left(t_{i}\right)$ of productive use of working time, respectively, teams of workers and CM\&M in total working time on the interval of planning $t_{i}$, characterize the level of labor organization and labour productivity in the implementation of ICP.

$$
\begin{gathered}
K_{Z}^{q}(i)=1-\frac{U_{z}\left(t_{i}\right)}{Q_{Z}^{0}\left(t_{i}\right)}, \\
K_{z}^{m}(i)=1-\frac{U_{Z}\left(t_{i}\right)}{Q_{z}^{0}\left(t_{i}\right)},
\end{gathered}
$$

Where $U_{z}^{r}\left(t_{i}\right), U_{z}^{m}\left(t_{i}\right)$, - respectively, the magnitudes of working time loss of teams of workers and CM\&Mon the project $\mathrm{z}$ on the interval of planning $t_{i} \cdot Q_{z}^{0 r}\left(t_{i}\right), Q_{z}^{0 m}\left(t_{i}\right)$ Respectively, the foundations of working time of workers' teams and CM\&Monthe $t_{i}$ interval of planning in the implementation of $z$ ICP.

At the tactical level of management ICP the creation of knowledge accumulation is carried out, which is a variant of the system status on the $t_{i}$ intervals of planning. In the construction the corrective management decisions affecting the terms and cost of construction, are usually taken at the end of the calendar month.

The knowledge accumulation consists of many options of organizational and technological models (OTM) and the corresponding calendar plans (CP), as well as the indicators characterizing the condition of the ICP on the $t_{i}$ interval of planning.

During the decision-making process, to analyze the condition of ICP, OTM isused first, corrected and based on the actual information about the progress of work. According to the analysis of time characteristics of the received $\mathrm{CP}$ and calculated integrated indicators of 
management efficiency ICP, a decision is made to enter or not the corrective effect in OTM to bring it to the desired date of construction.

Thus, on the $t_{i}$ interval of planningthe recorded indicators are entered into the knowledge accumulation, describing ICP before and after optimization of OTM. The following integrated indicators are used to assess the condition of the ISP option: The deviation of the actual construction period from the planned $\Delta T_{i}$ :

$$
\Delta T_{z i}=T_{z}^{F}\left(t_{i}\right)-T_{z}^{P}\left(t_{i}\right)
$$

Where $T_{z}^{F}\left(t_{i}\right)$ - the actual construction period on the $t_{i}$ interval of planning, $T_{z}^{P}\left(t_{i}\right)-$ planned term of construction.

2. Deviation of actual construction cost price of the planned

$$
\Delta S_{z}\left(t_{i}\right)=S_{z}^{F}\left(t_{i}\right)-S_{z}^{P}\left(t_{i}\right)
$$

Where $S_{z}^{F}\left(t_{i}\right)$ - the actual cost price according to management accounting on the $t_{i}$ interval ofplanning; $S_{z}^{P}\left(t_{i}\right)$ - planned cost price on the $t_{i}$ interval ofplanning. 3. Coefficient characterizing the deviation of the actual cost price from the planned on the $t_{i}$ interval ofplanning

$$
K_{Z}^{S}\left(t_{i}\right)=\left(1-\frac{S_{Z}^{F}\left(t_{i}\right)}{S_{Z}^{P}\left(t_{i}\right)}\right) * 100 \%
$$

With a positive value of the coefficient, there is a reduction of the actual cost price, relatively planned, with a negative value of the coefficient, respectively - an increase.

\section{Discussion section}

Inthe IMS "Construction" there is a mechanism of allowing to select any of OTM options from the previously listed in the accumulation of knowledge and the corresponding CP and to analyze the effectiveness of the decisions taken on a particular level of planning with their influence on the terms and the cost price of the facility.

Thus, in the IMS "Construction" there is a possibility of making decisions on the basis of precedents. The conclusion, based on precedents, is a decision-making method, which uses the knowledge of the previous situations or cases (precedents). Considering a new issue (this case) a similar precedent as a counterpart is being found. You can try to use its decision, perhaps adapting to the current case, instead of looking for a solution from the beginning each time. [14]

Detailed information about the daily labour costs and amount of work performed, recorded in the report card and work performance log, forming groups by structural elements and by performers - a team of workers. Then a detailed analysis of the use of working time can be carried out, and calculations of labour productivity (output, coefficient of performance of norms of production), and coefficient of using workers on their major works can be made. A similar analysis can be made on the use of the construction machinery and mechanisms.

\section{Conclusions}

Demand for materials, obtained on the basis of draft drawings data on the one hand, and information from the working place of production, recorded in the documents for the writeoff of materials allow to make a comparative analysis of the use of materials. These data produced in the section of $\mathrm{CE}$ and (or) kind of work allow to organize managerial 
accounting in the context of performers and of the whole object. If necessary, these data can be compared with the estimated or planned regulations. Information on productivity and actual consumption of material resources can be used in the development of management (inside the company) standards of the construction company.

Thus, in the IMS "Construction" there is a possibility of automated formation of the company's normative base of the resources consumption, including new previously not utilized technologies of work production and materials.

\section{References}

1. V.S. Stepin,The New Encyclopedia of Philosophy (2010)

2. Y.Z. Zipkin,Adaptation and learning in automatic systems(Nauka,Moscow,1968)

3. N.G. Zagoruiko,Applied methods of data analysis and knowledge(Sobolev Institute of Mathematics,Novosibirsk, 1999)

4. L.E. Karpov, V.N.Yudin, ISP RAS Preprint, 18(2006)

5. V.I.Skurikhin, V.A. Zabrodsky, Y.V. Kopeychenko,Design of adaptive control systems of production (Vishcha School,Kharkiv,1984)

6. A.A. Zhdanov, Proceedings of the Academy of Sciences 5, 127-134(1999)

7. I.V.Gontareva, M.A. Nemchinov, A.D. Popova,Mathematics and cybernetics in the economy (Economics, Moscow, 1975)

8. A. Bundy,Artificial Intelligence Techniques (Springer, Verlag, 1997)

9. K.D. Althof, E. Auriol, R. Barlette, M.Manago, AI Intelligence (1995)

10. S. S. Anand, J. G. Hughes, D. A. Bell and P. Hamilton, Aalborg (AIMDM'99),15-20 (1999)

11. V.V. Kuzmenko, D.V.Grishin, Bulletin NCSTU2(10),34 (2003)

12. G.G.Malinetsky, A.B.Potapov, A.V.Podlazov,Nonlinear dynamics: approaches, results (URSS, 2006)

13. E.W. Weisstein, Wolfram MathWorld11, 122 (2008)

14. http://www.businesstuning.ru/pm/pmprog/6-obzor-programm-dlya-upravleniyaproektamihtml

15. L.B. Zelentsov, A.L.Zelentsov, K.N.Ostrovsky, N.S.Sankova, Rostov State Civil Engineering University 8, 12 (2013)

16. L.B. Zelentsov, A.L. Zelentsov, K.N. Ostrovsky,Naukovedenie 3(12), 67 (2012) 